\title{
Prevalence Of Partial Edentulism and its Association to Age
}

\section{Research Article}

Dhinesh Kumar Sanggaya ${ }^{1}$, Visalakshi Ramanathan ${ }^{2 *}$

${ }^{1}$ Saveetha Dental College and Hospitals, Saveetha Institute of Medical and Technical Sciences, Saveetha University, Chennai, India.

${ }^{2}$ Senior Lecturer, Department of Periodontics, Saveetha Dental College and Hospitals, Saveetha Institute of Medical and Technical Sciences, Saveetha University, Chennai, 600077, India.

\section{Abstract}

Partial edentulism is a state of missing one or multiple teeth in the dental arch and can be due to several reasons which includes dental caries, periodontal disease, and trauma causing deterioration of general health and lifestyle of an individual. Few studies have been done regarding the behavior of the patients toward the consequences of partial edentulism and span of partial edentulism, but still, there is insufficiency of information regarding the clinical findings among various age groups of partially edentulous patients. The partial edentulism pattern has been observed globally in different populations.The aim of the present study was to assess the prevalence of partial edentulism based on kennedy's classification, evaluate if age is associated with partial edentulism. A retrospective evaluation was conducted in the Department of Prosthodontics, Saveetha Dental college by examining the patient records. The study sample consisted of 400 patients who were partially edentulous.Parameters recorded were age ,kennedy's classification.Chi square test for independence between Partial edentulism and age. Chi square value of the test statistic is 8.708 with corresponding $\mathrm{p}$ value 0.033 which is statistically significant denoting that there exists an association between age and partial edentulism among the study population. The most prevalent type of partial edentulism is Kennedy's class III with partial edentulism more common in 31-50 years age group.

Keywords: Age; Kennedy’s Classification; Partial Edentulism.

\section{Introduction}

Loss of tooth has an impact on an individual's quality of life in terms of social levels, psychological and biological factors. During recent decades the loss of teeth has decreased in many countries. Partial edentulism or complete tooth loss is prevalent worldwide among elderly. Tooth loss is a process where one or multiple teeth become loose and fall out. Losing teeth is undesirable and is the result of injury or disease like dental avulsion, tooth decay, and periodontal disease $[1,2]$. The condition of being toothless or missing one or multiple teeth is called edentulism [3, 4]. Some researchers observed that tooth loss occurs across all ages [5]. It is also found that the etiologic factor for tooth loss was dental caries followed by periodontal disease [6-8]. There are several classifications made for partial edentulism, however Kennedy's classification is the most widely accepted one $[9,10]$. This is due to the reason that it provides immediate visualization and recognition in prosthesis support recognition.
Among the causes of tooth loss are caries, tooth impaction, periodontal diseases, trauma, orthodontic treatment, neoplastic, supernumerary teeth, hypoplasia and cystic lesions [10,11]. Edentulism is an indicator of the oral health of a population. Many patients also regard edentulism as self-mutilating and may be a strong incentive to seek dental treatment. One of the most important oral health indicators is the ability to retain more teeth throughout life $[12,13]$. Edentulism or complete loss of teeth is common worldwide in older people [14]. Tooth loss has a major influence on biologic, social, and psychological levels of the oral healthrelated quality of life. The prevalence of tooth loss has declined considerably in various countries in the past two decades $[15,16]$. Several classifications have been suggested to classify partially edentulous arches to recognize possible combinations of teeth to ridges. At present, Kennedy's classification is considered the most broadly accepted classification for partially edentulous arches. Kennedy's classification offers immediate visualization, prosthesis

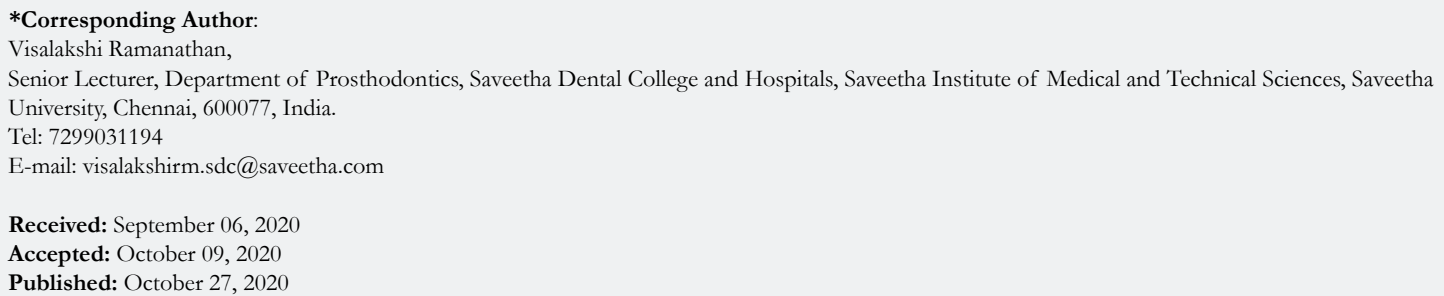

Copyright: Visalakshi Ramanathan 2020 . This is an open-access article distributed under the terms of the Creative Commons Attribution License, which permits unrestricted use, distribution and reproduction in any medium, provided the original author and source are credited. 
support recognition, and assessment of removable partial denture design features [17]. The patterns of tooth loss have been evaluated in many selected populations in different countries and the frequency of partial edentulousness seems to vary widely between different countries.

\section{Materials and Method}

This Study was performed in a university setting. The data for the study was collected by reviewing patient records from the Faculty of Prosthodontics, Saveetha Dental College and the data was assessed from the time period of June 2019 to April 2020 in this retrospective evaluation. After reviewing 2000 patient records 400 partially edentulous cases were included into the study.3 Ethical clearance was obtained from the Institutional Ethics Committee of Saveetha Dental College (SDC/SIHEC/2020/DIASDATA/0619-0320). The cross checking of data including digital entry and photographic data entry was done. The main advantage of this study was that the data was all prevalidated and the main disadvantage was that it was that only a single ethnicity of the population was studied in just one centre.After retrospective data collection done by the researcher. The data on following variables were tabulated: Patient ID number, Age and Kennedy's classification.The sample size consisted of 400 patients. A chi square test was performed to evaluate association between partial edentulism and age.

\section{Results and Discussion}

400 hundred patients are involved in this study out of which $9.5 \%$ are patients with Kennedy's class I, 15.25\% are Kennedy's class II and majority of the population belonged to Kennedy's class III with a percentage of $63.5 \%$ and Kennedy's class IV representing $11.75 \%$ of the study population (Graph 1). Among all three age groups 18 to 30,31 to 50 and 51 to 80 years ,Majority of the study population belonged to Kennedy's class III classification. $14.25 \%$ of the kennedys class III belonged to 18-30age group, 40.75\%(3150 age group) and $8.50 \%$ (51-80) age group (Graph 2). The reason for using a classification for this study for partially edentulous patients is to help in the description of partially edentulous cases. In the present study, Kennedy classification is used as it simplifies the description of partial edentulism, allows immediate visualization of the partially edentulous arch, provides a logical way to display the problems of design, and to simplify the application of basic principles of partial denture design. Aging of the world population is leading to a major readjustment in social and health services in most parts of the developed world.The age groups were (18-30), (31-50) and (51-80). Number of partially edentulous patients in the age group (18-30) was 91 and 225 patients from the age category (31-50). The remaining 84 are from the age group of (51-80). Kennedy's class III is the commonest among males and females as well. In this study it was observed that Kennedy's class III is the most common among all age groups and also the majority of all kennedy's classification belong to 31-50 years age group. Our results are similar to a study conducted by R.A Devishree et al it shows that prevalence of class III in both the gender and arch and in all age groups $[6,18]$. Similarly, in another study by Nayana Prabhu et al, Kennedy's class III is the most common class of partial edentulousness in the age group of 35-44 years old [19]. A study conducted by Javed Ashraf et al, age group 51 to 80 years old had the highest incidence of tooth loss and the most commonly occurring type of partial edentulousness was Kennedy's class III [20]. Small sample size and single centered study were the limitations in this study. Another limitation in this study is that

Table 1. Chi square test for independence between Partial edentulism and age. Chi square value of the test statistic is 8.708 with corresponding $\mathrm{p}$ value 0.033 which is statistically significant $(<0.05)$. There is a statistically significant difference between age and partial edentulism among the study population.

\begin{tabular}{|c|c|c|c|}
\hline \multicolumn{5}{|c|}{ Chi-Square Tests } \\
\hline & Value & df & Asymp Sig(2-sided) \\
\hline Pearson Chi-Square & 8.708 & 3 & 0.033 \\
\hline Likelihood Ratio & 9.116 & 3 & 0.028 \\
\hline Linear-by-Linear Association & 1.215 & 1 & 0.27 \\
\hline N of Valid Cases & \multicolumn{4}{|c|}{400} \\
\hline
\end{tabular}

Figure 1. Bar graph representing distribution of partially edentulous study participants based on Kennedy's classification. $\mathrm{X}$ axis represents Kennedy's classification and $\mathrm{Y}$ axis represents the percentage of partially edentulous study participants. Majority of the study population represented Kennedy's class III classification $(63.5 \%)$.

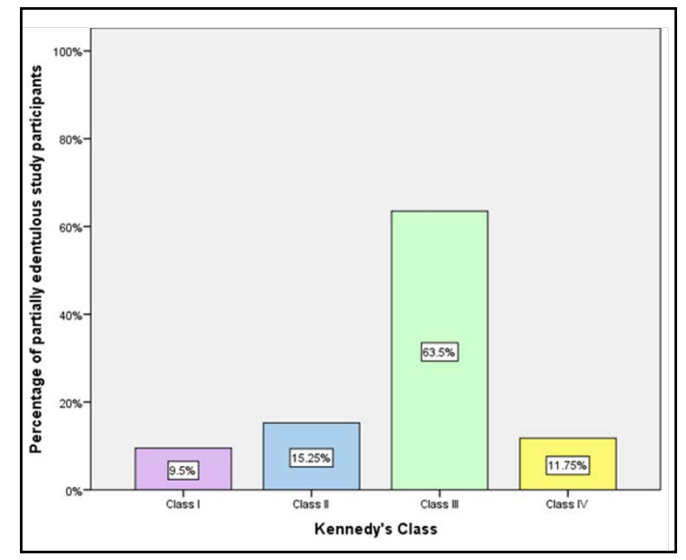


Figure 2. Bar graph representing the association between partial edentulism and age group. $\mathrm{X}$ axis represents Age group and $\mathrm{Y}$ axis represents the percentage of partially edentulous study participants.A Chi square analysis was performed to check for association between Partial edentulism and age. Chi square value 8.708 ,p value of $0.033(<0.05)$ statistically significant.Majority of the study population represented class III among all age groups.

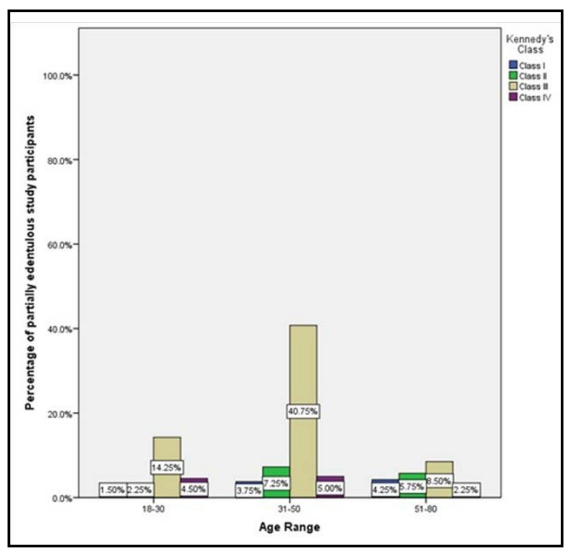

ethnic groups are not assessed.

Partial edentulism leads to poor quality of life and perception of well being if not treated at the right time. When not rehabilitated the consequences of partial edentulism tremendously increases the cost of the treatment. Socioeconomic factors as well as other factors like access to dental care, patient dentist ratio and age of the patient impact therapy for partial edentulism. The effect of partial edentulism on functional capacity to chew, bite has a direct effect on social life. Considering the economy at present it is necessary to prevent tooth loss in order to avoid the expenditure towards the treatment. The key is preventive dentistry.Clinically we suggest online oral health education promotions and dental education to control the progression of common dental caries and periodontitis with basics like creating awareness on flossing, fluoride application which can be a simple solution towards reducing tooth loss. Those patients who are already partially edentulous can be given temporary partial dentures with fewer visits so that consequences like drifting supraeruption can be avoided over a period of time which in turn will be helpful to the patients the. Patients can as well be followed up for implant therapy or fixed partial dentures in future.

\section{Conclusion}

Within the limits of the present study, the most prevalent type of partial edentulism is Kennedy's class III (saddle type)among all age groups.Partial edentulism is more common in the 31-50 years old age group. There is a statistically significant difference between partial edentulism and age in the current study.

\section{Acknowledgements}

The authors thank and acknowledge Saveetha Dental College for providing access to use the retrospective data from the Department of prosthodontics for the study.

\section{Author Contributions}

The authors have contributed to study design ,data collection, analysis of data,tabulation of results, manuscript typing and formatting. and critical reviewing.

\section{References}

[1]. Rana SB, Acharya B, Bhochhibhoya A, Sharma R, Acharya J, Mainali A. Patterns of partial edentulism based on Kennedy's classification among patients reporting to Nepal Medical College and Teaching Hospital. J. Kathmandu Med. Coll. 2018;17(4):153-7.

[2]. Jain AR, Nallaswamy D, Ariga P, Ganapathy DM. Determination of correlation of width of maxillary anterior teeth using extraoral and intraoral factors in Indian population: A systematic review. World J Dent. 2018 Jan;9:68-75.

[3]. Jyothi S, Robin PK, Ganapathy D. Periodontal health status of three different groups wearing temporary partial denture. Res J Pharm Technol. 2017;10(12):4339-42.

[4]. Duraisamy R, Krishnan CS, Ramasubramanian H, Sampathkumar J, Mariappan S, Navarasampatti Sivaprakasam A. Compatibility of Nonoriginal Abutments With Implants: Evaluation of Microgap at the Implant-Abutment Interface, With Original and Nonoriginal Abutments. Implant Dent. 2019 Jun;28(3):289-295.Pubmed PMID: 31124826.

[5]. Selvan SR, Ganapathy D. Efficacy of fifth generation cephalosporins against methicillin-resistant Staphylococcus aureus-A review. Res J Pharm Technol. 2016;9(10):1815-8.

[6]. Bruce I, Nyako EA, Adobo J. Dental service utilisation at the Korle Bu teaching hospital. Afr. J. OralHealth Sci. 2004;2(3):64-7.

[7]. Subasree S, Murthykumar K. Effect of Aloe Vera in Oral Health-A Review. Res J Pharm Technol. 2016;9(5):609-12.

[8]. Ranganathan H, Ganapathy DM, Jain AR. Cervical and Incisal Marginal Discrepancy in Ceramic Laminate Veneering Materials: A SEM Analysis. Contemp Clin Dent. 2017 Apr-Jun;8(2):272-278.Pubmed PMID: 28839415.

[9]. Vijayalakshmi B, Ganapathy D. Medical management of cellulitis. Research Journal of Pharmacy and Technology. 2016;9(11):2067-70.

[10]. Kannan A. Effect of Coated Surfaces influencing Screw Loosening in Implants: A Systematic Review and Meta-analysis. World. 2017 Nov;8(6):496502.

[11]. Ashok V, Suvitha S. Awareness of all ceramic restoration in rural population. Res J Pharm Technol. 2016;9(10):1691-3.

[12]. Ashok V, Nallaswamy D, Benazir Begum S, Nesappan T. Lip Bumper Prosthesis for an Acromegaly Patient: A Clinical Report. J Indian Prosthodont Soc. 2014 Dec;14(Suppl 1):279-82.Pubmed PMID: 26199531.

[13]. Venugopalan S, Ariga P, Aggarwal P, Viswanath A. Case Report: Magnetically retained silicone facial prosthesis. Niger J Clin Pract. $2014 \mathrm{Mar}$ 27;17(2):260-4.

[14]. Kannan A, Venugopalan S. A systematic review on the effect of use of impregnated retraction cords on gingiva. Res J Pharm Technol. 2018;11(5):2121-6.

[15]. Basha FYS, Ganapathy D, Venugopalan S. Oral Hygiene Status among Pregnant Women. Res J Pharm Technol. 2018;11:3099.

[16]. Ajay R, Suma K, Ali SA, Kumar Sivakumar JS, Rakshagan V, Devaki V,. Effect of Surface Modifications on the Retention of Cement-retained Implant Crowns under Fatigue Loads: An In vitro Study. J Pharm Bioallied Sci. 2017 Nov;9(Suppl 1):S154-S160.Pubmed PMID: 29284956.

[17]. Ganapathy D, Sathyamoorthy A, Ranganathan H, Murthykumar K. Effect of Resin Bonded Luting Agents Influencing Marginal Discrepancy in All Ceramic Complete Veneer Crowns. J Clin Diagn Res. 2016 Dec;10(12):ZC67ZC70.Pubmed PMID: 28209008. 
[18]. Jeyapalan V, Krishnan CS. Partial Edentulism and its Correlation to Age, Gender, Socio-economic Status and Incidence of Various Kennedy's Classes- A Literature Review. J Clin Diagn Res. 2015 Jun;9(6):ZE14-7.Pubmed PMID: 26266237.

[19]. Prabhu N, Kumar S, D'souza M, Hegde V. Partial edentulousness in a rural population based on Kennedy's classification: an epidemiological study. J
Indian Prosthodont Soc. 2009 Jan 1;9(1):18.

[20]. Ashraf J, Jain AR, Ariga P, Nallaswamy D. Prevalence of partial edentulousness and treatment needs in rural population of South India. World J Dent. 2017;8(3):213-7. 